\section{Short-sighted to cut environment posts}

Australia's premier governmentfunded science agency, CSIRO, is shedding jobs in environmental science -100 scientists from the climate-sciences division alone face imminent job loss. The perception that environmental research is unprofitable has already rendered it victim to four years of government cuts. Evidently, the promise of significant savings from science-based environmental remediation has yet to resonate with decision-makers.

Other major CSIRO job losses affect research on sustainable management of the nation's terrestrial and aquatic ecosystems and biodiversity. James Cook University in Queensland intends to axe $25 \%$ of its academic staff in the environmental sciences. Effective research organizations such as Land and Water Australia have been disbanded. And past cuts have already translated into weakened environmental regulation and management.

Australia is vulnerable to climate-change effects and has rapid population growth. It leads the world in recent extinctions of terrestrial mammals, and has vast areas that are in urgent need of restoration after widespread intensive land clearing, livestock overgrazing and mining.

Anti-environment policies and further destruction of Australia's research capability are threatening to destroy its priceless natural heritage.

David Lindenmayer The Australian National University, Canberra, Australia. david.lindenmayer@anu.edu.au

\section{China draws lines to green future}

To conserve the strategic integrity of its environment, China has drawn up a system of 'Red Lines'. These denote the total minimum areas of various land-use types nationally and regionally, without specifying their exact locations.

Coming after Red Lines that were created to protect cropland and forest habitats, the latest Red Line will safeguard China's vast biodiversity, environmental resources and ecosystem services. This could consolidate the shift in the country's environmental strategy, which is moving away from networks of protected areas and short-term ecological restoration towards longer-term conservation of entire landscapes.

We propose that the area marked by the latest Red Line (see go.nature.com/na6ry6; in Chinese) should equal at least 496 million hectares. This would incorporate the areas covered by China's existing nature-reserve network and three recent, overlapping, landscape-scale conservation schemes. Within these, 'priority biodiversity conservation areas', 'important ecosystem-function areas' and 'key ecosystem-service function areas' have been designated for flood protection, erosion control, biodiversity conservation and ecosystem-service provision.

Direct government payments for ecosystem-service provisions and adjustments to imbalances in designations, particularly in China's eastern provinces, should underpin this initiative.

Sang Weiguo Minzu University of China; and Institute of Botany, Chinese Academy of Sciences, Beijing, China.

Jan C. Axmacher University College London, UK. j.axmacher@ucl.ac.uk

\section{Six principles for EU peer review}

The European Union Agencies Network for Scientific Advice (EU-ANSA) is a group of $11 \mathrm{EU}$ agencies that provides scientific information for institutions and national authorities in Europe. It has recently assessed its peerreview practices and drawn up guidelines that we hope will support the agencies' work and contribute to the debate on changes to peer-review methods, particularly when there are implications for policymaking.

The context in which EU agencies provide scientific advice and technical support is highly specific. It requires a special approach to peer review that addresses particular challenges, such as ensuring reviewers' motivation, independence and international perspective.

The EU-ANSA collaboration has outlined six guiding principles (see go.nature. com/bqb7jp). These focus on: defining the process so that it is widely accepted; recruiting high-quality expertise; achieving credibility and avoiding bias using a transparent process; the provision of adequate resources; the availability of adequate technical support; and integration with established agency processes for ensuring good quality and performance in work.

William Cockburn European Agency for Safety and Health at Work, Bilbao, Spain.

Hubert Deluyker European Food Safety Authority, Parma, Italy. cockburn@osha.europa.eu

\section{Hasty publication compromises rigour}

The period between submitting a paper and its publication can sometimes exceed the time invested in achieving the results (see Nature 530, 148-151; 2016). Meanwhile, acquiring funding still hinges on clocking up publications in journals with high impact factors. These pressures pose a difficult choice for researchers, especially those in the early stages of their careers.

To compete for a faculty position or an independent grant, a PhD student must publish a handful of papers and then keep the ball rolling as a postdoc with at least one paper every year. The importance of publishing fast is hammered home during this period when, in our view, the emphasis should instead be on the reproducibility of results.
In this battle for survival and growth, it is scientific rigour that might pay the price.

Even improvements in performance indicators - using citation counts, for example are of little help to an early-career researcher. We need to move away from the 'publish or perish' ethos and towards incentives that reward scientific quality.

Shraddha Madhav Karve Indian Institute of Science Education and Research, Pune, India.

Madhur Mangalam University of Georgia, Athens, USA. madhur.mangalam@uga.edu

\section{Biodiversity central to food security}

At the fourth plenary session of the Intergovernmental Panel on Biodiversity and Ecosystem Services (IPBES) last month, the thematic assessment on sustainable biodiversity use was referred for a second scoping by experts. I suggest that the new analysis needs to include biodiversity's contribution to ecosystem services that are essential to agricultural sustainability and food security.

Agricultural ecosystems are directly linked to human and environmental health (D. Tilman and M. Clark Nature 515, 518$522 ; 2014)$. They are essential to the IPBES' ambition to influence progress on the United Nations Sustainable Development Goals. Furthermore, by 2050, the food supply for 9.6 billion people will depend on the sustainable use of agricultural biodiversity and its multiple ecosystem services (see go.nature.com/7ympnb).

A narrow scope that focuses on harvesting wild, uncultivated species will fail to capture biodiversity's importance to ecosystem services. Instead, we need a systems-based approach (see J. Liu et al. Science http://doi. org/627; 2015).

Fabrice DeClerck Bioversity

International - CGIAR,

Montpellier, France.

f.declerck@cgiar.org 